\title{
The Most Important Failure Investigation
}

\author{
Daniel J. Benac
}

Submitted: 21 January 2014/ Published online: 22 February 2014 (C) ASM International 2014

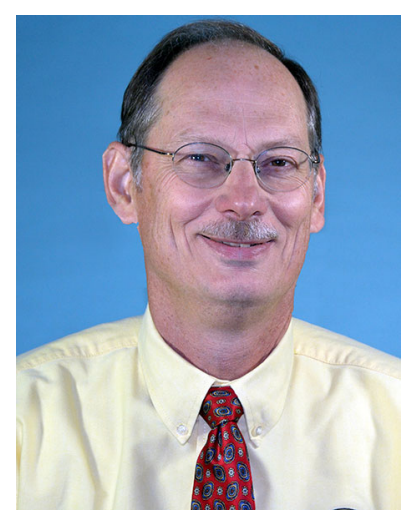

Failure investigators have opportunities to work on some very interesting problems, materials, and designs. For the investigator who solves the mysteries of failures and applies the laws of science and materials behavior, some investigations may appear more interesting and significant than others. Yet, that alone should not define the "importance" of conducting an investigation, nor should it determine the amount of effort that should be expended in understanding what happened. In an indirect way this was reinforced for me after giving a talk to engineering students.

Last fall, I gave a guest lecture at Abilene Christian University (ACU) in Abilene, Texas. The school had recently started an engineering program, and I was invited to enlighten and excite the students about engineering, science, and materials engineering. I entitled my lecture "The Many Hats That a Materials Engineer Wears" and

talked about how materials/metallurgical engineers often are called upon to perform multi-discipline services such as being a design engineer, manufacturing engineer, process engineer, inspection engineer, or quality control engineer, as well as a troubleshooter and failure analyst.

I discussed how the materials/metallurgical engineer often conducts failure investigations and works to prevent failures of components. I described a few case histories to illustrate the diversity and challenges that an investigator faces when something malfunctions, fails, or does not satisfy its intended design and function. After the talk, a freshman engineering student asked me the following question: "What is the most interesting failure investigation that you've conducted?" I thought a moment and quickly played a video in my mind of over 30 years of investigating a diversity of failures of different materials for different industries and for a variety of customers. These interesting investigations flashed through my mind:

- The very first investigation I did while working in the oil and gas industry: a pressure relief valve, low-alloy spring failed due to corrosion-induced torsional fatigue. I recalled this investigation because I learned how corrosion can cause failures.

- An F-16 jet engine blowout occurred, causing hot engine gas impingement on the aluminum nacelle skin. This investigation was interesting because of the ramifications on the airworthiness of the aircraft, and because it required me to travel to the US. Air Force base in Seoul, South Korea to do a field inspection.

- A medical device failure of superelastic, shape-memory nitinol brachytherapy wire containing a radioactive isotope source. The small-diameter wire failed due to fatigue and resulted in the radioactive source falling out of the wire. This failure was interesting because the 
properties of the superelastic material and the complexity of the human body both fascinated me, and the investigation involved radioactive material.

- A fiberglass hoop-wound compressed natural gas cylinder failed in a bus, causing damage that looked like a bomb had exploded in a war zone. No injuries occurred, but the blast had the potential to produce a mass casualty incident. This investigation was interesting to me because the findings were used to improve cylinder design and maintenance practices, thus reducing the potential for risk.

- A hydrogen gas explosion occurred in a carbon steel pipe that had suffered from high temperature hydrogen attack (HTHA). This failure was interesting because the team determined how a material can be altered by a chemical process and also identified what safeguards would be needed to reduce the risk of failure of that material.

I shared a few such interesting cases with the class. However, while driving back through West Texas, the freshman's question continued to roll around in my mind like the tumbleweeds that occasionally blew across the road. I found myself wondering how should a failure investigator approach each investigation? Especially, those that may not be as interesting as the ones mentioned above. My thoughts focused on another question: Are some investigations more important than others, and if so, do they require more attention to detail than others that appear to not be as important or interesting?

This question is a relevant question for failure analysts because not every investigation is "interesting" and some investigations can even seem routine. Yet, I propose that every investigation is important and should receive our full attention.

We investigators should remind one another, and particularly young engineers, that each failure investigation we work on-in which something has fallen short of the intended design - is an important investigation. From a designer's perspective, a component, part, or system is intended to perform a specific function under prescribed operating and design conditions. It is "important" that the design functions as intended, but if that design is compromised, then malfunction and failure occurs. The equipment, part, or system has fallen short.

The failure investigator can and should provide findings to explain what went wrong. To restore the design to proper function is what is most important! The level of attention to detail should not depend on whether the investigation is routine or interesting, on the size of the part or the consequence of the failure, or in a lawsuit, the case value. A small bolt that fails can have great or very little consequence and researching the cause of its failure can seem to be routine, yet it deserves absolute diligence and resolve to determine how and why it failed.

Keep in mind, when that next failure occurs and you begin your investigation, that it may or may not be the most interesting failure. It may or may not have significant consequences. You may be tempted to give it less attention than a higher profile case or more interesting failure. But at the moment you start the investigation, it is your most important failure investigation. Your findings will have value, and your inquiry has the capacity to explain what happened so that the equipment can perform as designed and intended. Thus, we investigators must give each investigation the full attention needed and deserved.

The Journal of Failure Analysis and Prevention publishes many articles, case histories, and lessons learned, to help investigators and engineers understand how failures can occur. These articles are written, submitted, reviewed, and selected by the editorial board to help educate and enlighten the readers. We hope that you find them all interesting and that each article presents findings from an investigation that was important to someone at the time of that investigation. Someday those same findings may also be important to you. 